\title{
Erratum to: Diacerein: Benefits, Risks and Place in the Management of Osteoarthritis. An Opinion-Based Report from the ESCEO
}

\author{
Karel Pavelka ${ }^{1}$ Olivier Bruyère ${ }^{2} \cdot$ Cyrus Cooper $^{3} \cdot$ John A. Kanis ${ }^{4} \cdot$ \\ Burkhard F. Leeb ${ }^{5} \cdot$ Emmanuel Maheu $^{6} \cdot$ Johanne Martel-Pelletier $^{7}$. \\ Jordi Monfort ${ }^{8} \cdot$ Jean-Pierre Pelletier $^{7} \cdot$ René Rizzoli $^{9} \cdot$ Jean-Yves Reginster $^{2}$
}

Published online: 27 March 2017

(C) Springer International Publishing Switzerland 2017

\section{Erratum to: Drugs Aging (2016) 33:75-85 \\ DOI 10.1007/s40266-016-0347-4}

In the original publication the affiliation for John A. Kanis was incorrectly published.

This previously read: WHO Collaborating Centre for Metabolic Bone Diseases, University of Sheffield Medical School, Sheffield, UK.

Should read: Centre for Metabolic Bone Diseases, University of Sheffield Medical School, Sheffield, UK.

The online version of the original article can be found under doi:10.1007/s40266-016-0347-4.

Olivier Bruyère

olivier.bruyere@ulg.ac.be

1 Institute of Rheumatology and Clinic of Rheumatology, Charles University, Prague, Czech Republic

2 Department of Public Health, Epidemiology and Health Economics, University of Liège, Liège, Belgium

3 MRC Lifecourse Epidemiology Unit and NIHR Nutrition Biomedical Research Centre, University of Southampton, Southampton, UK

4 Centre for Metabolic Bone Diseases, University of Sheffield Medical School, Sheffield, UK

5 2nd Department of Medicine, State Hospital Stockerau, Centre for Rheumatology, Lower Austria, Karl Landsteiner Institute for Clinical Rheumatology, Stockerau, Austria
6 Rheumatology Department, AP-HP, St-Antoine Hospital, Paris, France

7 Osteoarthritis Research Unit, University of Montreal Hospital Research Centre (CRCHUM), Notre-Dame-Hospital, Montreal, Canada

8 Rheumatology Service, Hospital del Mar, Universitat Autònoma de Barcelona, Barcelona, Spain

9 Division of Bone Diseases, Geneva University Hospital and Faculty of Medicine, Geneva, Switzerland 